\title{
IKLIM KELAS DI SEKOLAH DASAR NEGERI 10 GANTING, KOTO TANGAH, KOTA PADANG
}

\author{
Hadiyanto, Martini \\ Universitas Negeri Padang, SD Negeri 10 Ganting, Padang \\ hadiyanto@fip.unp.ac.id
}

\begin{abstract}
Abstrak
Penelitian kolaborasi ini bertujuan untuk mengetahui dan membandingkan iklim kelas yang dialami (actual climate) dengan iklim kelas yang diinginkan (preferred climate) peserta didik di kelas IV, V dan VI Sekolah Dasar Negeri 10 Ganting, Kecamatan Koto Tangah Kota Padang, Sumatera Barat. Responden penelitian berjumlah 78 orang, masing-masing peserta didik di ketiga kelas tersebut merespon dua macam angket. Alat ukur iklim kelas actual form diadministrasikan terlebih dahulu untuk mengetahui iklim kelas yang dialami peserta didik, kemudian diikuti dengan alat ukur iklim kelas preferred form untuk mengukur iklim kelas yang diinginkan peserta didik. Setelah data yang terkumpul diolah dan dianalisis maka dapat diketahui bahwa beberapa skala iklim kelas yang dialami (actual climate) peserta didik kelas IV, V dan VI SD 10 Ganting tidak jauh berbeda dengan iklim kelas diinginkan (preferred climate). Namun demikian, skala cohesiveness dan satisfaction pada preferred climate di kelas $\mathrm{V}$ lebih tinggi dibandingkan dengan yang dialami peserta didik (actual climate). Untuk itu, diperlukan langkah-langkah treatment untuk meningkatkan kedua skala tersebut agar iklim kelas sesuai dengan yang diinginkan peserta didik.
\end{abstract}

Kata kunci: iklim kelas, sekolah dasar, keakraban, kepuasan, demokrasi, kecepatan, kesulitan, formalitas

\section{CLASSROOM CLIMATE AT PUBLIC ELEMENTARY SCHOOL 10 GANTING, KOTO TANGAH, KOTA PADANG}

\author{
Hadiyanto, Martini \\ Universitas Negeri Padang, SD Negeri 10 Ganting, Padang \\ hadiyanto@fip.unp.ac.id
}

\begin{abstract}
This collaborative study aims to determine and compare the climate of the class experienced (actual climate) with the desired class climate (preferred climate) by students in class IV, V and VI at Public Elementary School Number 10, Sub-District Koto Tangah Padang, West Sumatra. Research respondents were 78 people, each student in the three classes responded to two kinds of questionnaires. The actual form of classroom climate instrument was administered first to know class climate experienced by students, then followed by preferred form of classroom climate instrument to measure climate of class desired by students. After the collected data were processed and analyzed it can be seen that some actual classroom climate of class IV, V and VI of Public Elementary School No. 10 Ganting are not much different from the preferred climate. Nevertheless, the scale of cohesiveness and satisfaction in preferred climate in class $V$ is higher than that actual climate. Therefore, treatment steps are needed to improve both scales so that the classroom climate in accordance with the desired students.
\end{abstract}

Keywords: class climate, elementary school, familiarity, satisfaction, democracy, speed, difficulty, formality. 


\section{Pendahuluan}

Diantara bidang-bidang kajian yang dapat di-share kepada para guru utuk peningkatan kualitas pembelajaran adalah perbaikan iklim kelas melalui penelitian tindakan kelas oleh guru yang bersangkutan. Penelitian tentang perbaikan iklim kelas telah lama dilaksanakan di Amerika sejak tahun 1979 oleh Moos (1979), dan di Australia dilakuakn oleh Fisher \& Fraser (1982). Dari kedua Negara tersebut, penelitian iklim kelas berkembang ke Spanyol, Belanda, Canada yang dilakukan oleh Fisher \& Nair (n.d.), di Singapura dilakukan oleh Khine (2001), dan Zedan (2010). Dari berbagai studi pengembangan iklim kelas tersebut, telah diidentifikasi kurang lebih terdapat 46 skala iklim kelas yang digunakan oleh para ahli dalam melakukan perbaikan iklim kelas (Hadiyanto, 2004; Hadiyanto, 2016). Para guru dapat leluasa memilih skala-skala tertentu yang perlu diperbaiki sesuai dengan kebutuhan. Kajian tentang person environment fit menekankan bahwa iklim kelas yang sesuai dengan keinginan peserta didik (preferred) menghasilkan proses pembelajaran yang lebih berkualitas (Fraser \& Fisher, 1983).

Meskipun di Negara lain telah berkembang dengan maksimal, penelitian perbaikan iklim kelas tersebut selama ini belum banyak dilakukan di Indonesia, lebihlebih lagi di Sumatera Barat. Beberapa penelitian iklim kelas yang dilakukan masih sebatas pada studi eksploratif, misal-nya Wahyuningrum (2008), atau pun penelitian korelasional seperti yang dilakukan oleh Tarmidzi (2006).

Penelitian yang telah dilaksanakan Hadiyanto \& Mukti (1997), serta Hadiyanto \& Kumaidi (1998), telah menghasilkan alat ukur iklim kelas untuk sekolah dasar yang terstandar. Alat ukur iklim kelas itu dapat digunakan untuk membantu guru sekolah dasar dalam perbaikan proses pembelajaran di kelas melalui perbaikan skala-skala yang ada seperti keakraban (cohesivenenss), kepuasan (satisfaction), kecepatan (speed), formalitas (formality), kesulitan (difficulty), dan demokrasi (democracy). Para peneliti seperti Muhammad, Hadiyanto, \& Nurli
(1998), dan Sutjipto \& Hadiyanto (2003) sebenarnya telah memulai menggunakan alat ukur yang telah dikembangkan dan divalidasi tersebut. Namun demikian, studistudi tersebut masih perlu direplikasi dan diperkaya dengan perbaikan skala-skala yang lebih bervariasi sesuai dengan kebutuhan kelas yang bersangkutan.

Dari hasil penelitian-penelitian yang telah dilakukan baik di Indonesia maupun di luar negeri, para peneliti memperoleh kesimpulan bahwa iklim kelas mempunyai korelasi atau kontribusi dengan variablevariabel lainnya seperti tingkah laku peserta didik (Fisher, 1990), variable prestasi belajar (Hyman, 1980), (Fraser, 1986; Falsario, 2014).

Di samping perlunya penelitian tentang iklim kelas di Indonesia yang pada umumnya masih dilakukan oleh para dosen di perguruan tinggi, kebiasaan meneliti dan menulis artikel harus disampaikan kepada para guru di sekolah. Para guru, di samping harus menambah ilmu pengetahuannya lewat kuliah atau cara lainnya, mereka perlu mendapatkan sentuhan-sentuhan pembaharuan dari perguruan tinggi untuk pembaharuan dan mengakselesari agar proses pembelajaran di kelas menjadi lebih efektif dan efisien. Di samping itu, para guru juga perlu mendapatkan bimbingan dalam proses kenaikan pangkatnya yang senantiasa memperoleh berbagai kendala keilmuan, kendala teknis, maupun kendala karakter, sehingga menghambat karir mereka. Ribuan guru di Tasikmalaya misalnya, harus gagal naik pangkat karena plagiarisme (Info-Tasikmalaya, 2017), sehingga Menteri Pendidikan dan Kebudayaan RI mengingatkan agar para guru di Indonesia tidak lagi melakukan kegiatan plagiarisme (JPP, 2017). Hal tersebut mestinya tidak harus terjadi manakala para guru memperoleh pengetahuan dan kapasitas yang memadai dalam menyusun karya ilmiah, maupun hasil penelitian dalam rangka meninngkatkan kualitas pembelajaran yang mereka ampu.

Beranjak dari permasalahan di atas, peneliti terpanggil untuk berbagi pengalaman dan keahlian dalam memanfaatkan 
hasil penelitian untuk pengembangan keilmuan ataupun untuk peningkatan kualitas pembelajaran melalui penelitian dan penulisan karya ilmiah dalam rangka menunjang karir para guru di sekolah. Berdasarkan uraian yang telah disampaikan, penelitian kolaborasi ini bertujuan untuk mengetahui dan membandingkan iklim kelas yang dialami (actual climate) dengan iklim kelas yang diinginkan (preferred climate) peserta didik di kelas IV, V dan VI Sekolah Dasar Negeri 10 Ganting, Kecamatan Koto Tangah Kota Padang, Sumatera Barat.

\section{Metode Penelitian}

Penelitian ini sebenarnya merupakan tahap awal dari suatu penelitian tindakan kelas sebagai kegiatan multy purposes, dalam rangka perbaikan proses pembelajaran dan peningkatan kualitas guru dalam penelitian serta penulisan karya ilmiah. Untuk itu, berbagai metode akan digunakan seperti ceramah dan tanya jawab, focused group discussion, pemecahan masalah bersama, serta penyelesaian masalah masingmasing guru dibantu dengan tim pengabdian masyarakat dan nara sumber lainnya.

Penelitian ini mengadaptasi lima langkah perbaikan iklim kelas yang disarankan oleh Fraser, Seddon, \& Eagleson (1982), dan Fraser (1986) yang berisi lima langkah yaitu: penilaian awal (assessment), umpan balik (feedback), refleksi dan diskusi (reflection and discussion), campur tangan perbaikan (intervention) dan penilaian ulang (reassessment). Namun demikian, karena penelitian ini merupakan langkah multi years, maka langkah-langkah di atas diadaptasi dan dilaksanakan menjadi delapan langkah yang kelompokkan ke dalam tiga tahap, masing-masing tahap selama satu tahun. Pada tahun pertama, kegiatan yang dilakukan adalah sebagai berikut.

1) Pengenalan pendahuluan tentang pentingnya iklim kelas untuk perbaikan kualitas pembelajaran. Pada tahap ini peneliti melakukan sosialisasi kepada para guru SD Kelas IV, V dan VI SD Negeri 10 Ganting Kecamatan Koto Ta- ngah tentang pentingnya kualitas pembelajaran. Peneliti memperkenalkan perbaikan iklim kelas melalui penelitian tindakan kelas yang dapat digunakan untuk peningkatan kualitas pembelajaran. Sosialisasi dilaksanakan dengan mengumpulkan para guru dalam suasana yang kondusif sehingga memungkinkan terjadinya interaksi dua arah yang akrab antara guru dengan peneliti dan menghilangkan jarak diantara mereka.

2) Penilaian awal (assessment). Kegiatan penjaringan data ini dilakukan untuk memotret iklim kelas IV, V, VI SD Negeri 10 Ganting dengan menggunakan alat ukur iklim kelas yang telah disusun oleh Hadiyanto \& Mukti (1997). Alat ukur iklim kelas terdiri dari actual form untuk menjaring informasi tentang iklim kelas yang dialami pada saat penjaringan data, dan preferrd form untuk menjaring informasi tentang iklim kelas yang diinginkan oleh peserta didik. Adapun responden penelitian ini sebanyak 24 peserta didik kelas IV, 29 peserta didik kelas $\mathrm{V}$, dan 25 peserta didik kelas VI.

3) Umpan balik (feedback) hasil asesmen. Setelah data diolah menghasilkan informasi, maka kegiatan yang dilakukan adalah menyampaikan hasil pengolahan data kepada guru kelas IV, V dan VI SD Negeri 10 Ganting Kecamatan Koto Tangah Kota Padang.

Langkah-langkah berikutnya yaitu refleksi dan diskusi (reflection and discussion). campur tangan perbaikan (intervension), penilaian ulang (reassessment), serta menyusun artikel online hasil penelitian tindakan pada jurnal online di Universitas Negeri Padang, atau jurnal di universitas lainnya akan dilaksanakan pada tahuntahun berikutnya.

\section{Hasil Penelitian dan Pembahasan}

Hasil penelitian ini merupakan hasil dari langkah kedua di atas yang dilaksanakan baru pada tahun pertama. Setelah 
data ditabulasi, diolah dan dianalisis, maka hasil analisis perbandingan iklim kelas actual dan preferred dari ketiga kelas yang menjadi sasaran penelitian, seperti yang tertuang pada Tabel $1 .$.

Tabel 1. Sebaran Responden dan Perbandingan Iklim Kelas IV, V dan VI SDN 10 Ganting Koto Tangah Padang (Actual dan Preferred Form)

\begin{tabular}{|c|c|c|c|c|c|c|c|c|}
\hline Kelas & Jml Resp & $\begin{array}{l}\text { Actual/ } \\
\text { Preferred }\end{array}$ & Cohes & Satisf & Speed & Diffclty & Form & Democ \\
\hline \multirow{2}{*}{ IV } & 24 & Actual & 13.00 & 13.09 & 9.36 & 9.64 & 12.64 & 11.73 \\
\hline & 24 & Preferred & 13.64 & 12.91 & 10.18 & 10.00 & 12.55 & 11.91 \\
\hline \multirow{2}{*}{$\mathbf{V}$} & 29 & Actual & 10.73 & 11.64 & 8.00 & 8.64 & 12.73 & 11.73 \\
\hline & 29 & Preferred & 12.64 & 12.64 & 8.73 & 9.55 & 12.82 & 12.27 \\
\hline \multirow{2}{*}{ VI } & 25 & Actual & 11.64 & 12.73 & 9.55 & 7.73 & 12.27 & 11.18 \\
\hline & 25 & Preferred & 12.45 & 12.91 & 9.55 & 8.55 & 12.64 & 11.18 \\
\hline
\end{tabular}

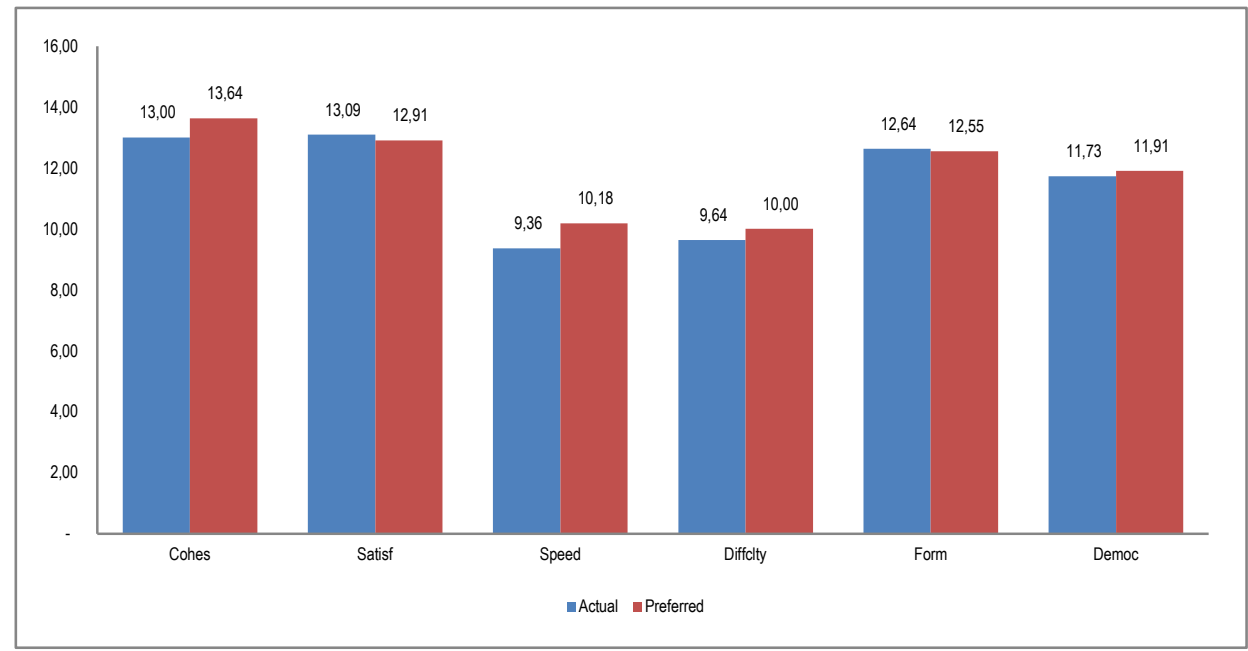

Gambar 1. Iklim Kelas yang Dialami (Actual) dan yang Diharapkan (Preferred) Peserta Didik Kelas IV SD Negeri Ganting, Koto Tangah, Padang

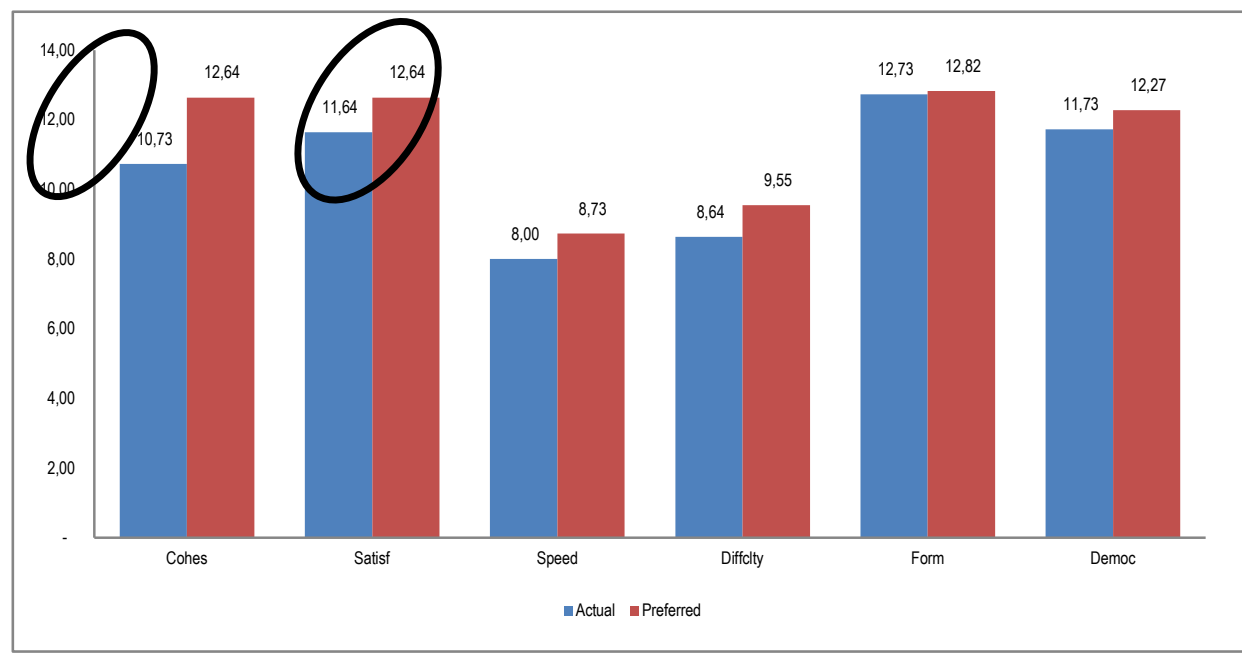

Gambar 2. Iklim Kelas yang Dialami (Actual) dan yang Diharapkan (Preferred) Peserta Didik Kelas V SD Negeri 10 Ganting, Koto Tangah, Padang 


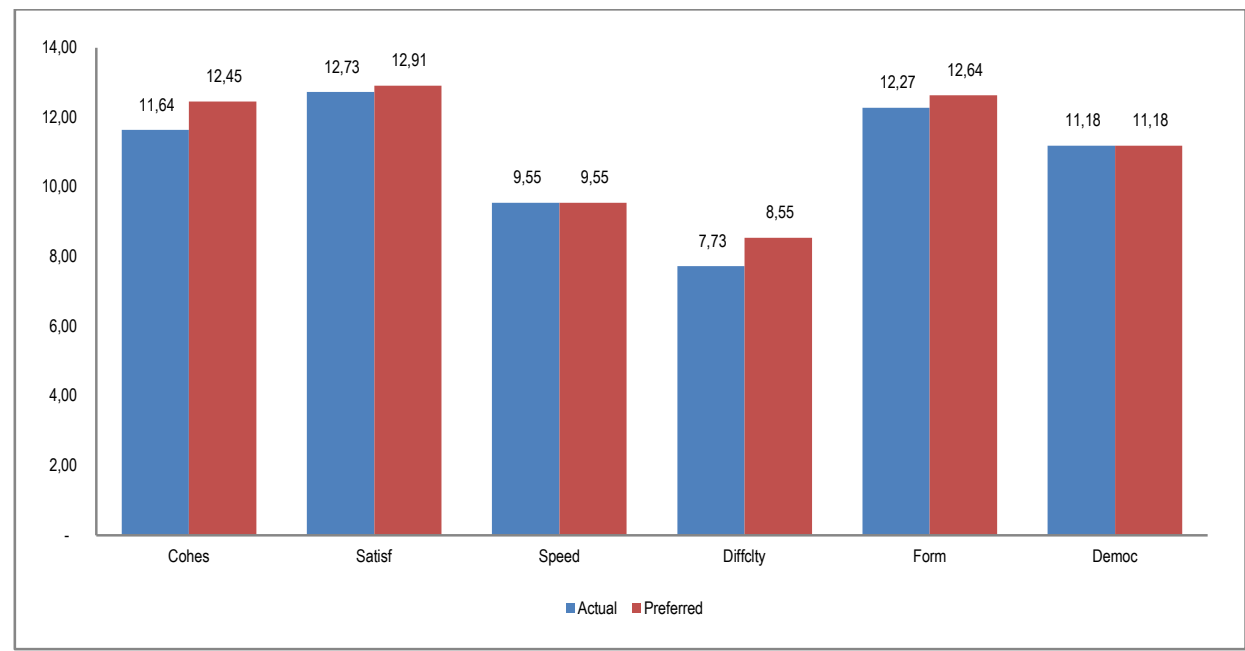

Gambar 3. Iklim Kelas yang Dialami (Actual) dan yang Diharapkan (Preferred) Peserta Didik Kelas VI SD Negeri 10 Ganting, Koto Tangah, Padang

Untuk lebih memudahkan dalam melakukan perbandingan antara iklim kelas actual dengan iklim kelas preferred, maka hasil analisis tersebut akan dituangkan dalam bentuk grafik perbandingan sebagai berikut.

Iklim Kelas IV Sekolah Dasar Negeri 10 Ganting

Hasil pengolahan data perbandingan antara iklim kelas actual form dengan preferred form di kelas IV Sekolah Dasar Negeri 10 Ganting dapat dilihat pada grafik yang disajikan pada Gambar 1 .

Dari grafik pada Gambar 1 tersebut dapat diketahui bahwa secara umum hampir tidak ada bedanya antara skala-skala iklim kelas yang dialami (actual climate) dengan iklim kelas yang diinginkan (preferred climate) oleh peserta didik. Bahkan dalam skala demokrasi, perbedaan antara actual dengan preferred dapat dikatakan nyaris tidak ada (antara 11.73 dengan 11.91).

Iklim Kelas V Sekolah Dasar Negeri 10 Ganting

Hasil pengolahan data perbandingan antara iklim kelas actual form dengan preferred form di kelas V Sekolah Dasar Negeri 10 Ganting dapat dilihat pada grafik yang disajikam pada Gambar 2 .

Dari grafik pada Gambar 2 dapat diketahui bahwa pada empat skala ilklim kelas, yaitu speed, difficulty, formality dan democracy, perbedaan antara actual dengan preferred climatenya dapat dikatakan hampir tidak ada bedanya. Namun demikian, ada dua skala yang mempunyai perbedaan yang cukup mencolok antara iklim yang dialami (actual climate) dengan iklim yang diinginkan (preferred climate) yaitu skala cohessevenes dan skala satisfaction. Dengan demikian, kedua skala tersbut harus menjadi perhatian guru untuk diambil langkahlangkah perbaikannya.

Iklim Kelas VI Sekolah Dasar Negeri 10 Ganting

Hasil pengolahan data perbandingan antara iklim kelas actual form dengan preferred form di kelas VI Sekolah Dasar Negeri 10 Ganting dapat dilihat pada grafik yang disajikan pada Gambar 3.

Dari grafik pada Gambar 3 tersebut dapat diketahui bahwa secara umum hampir tidak ada bedanya antara iklim kelas yang dialami (actual climate) dengan iklim kelas yang diinginkan (preferred climate) oleh peserta didik.

\section{Simpulan}

Hasil penelitian kolaborasi dari ketiga kelas tersebut di atas dapat diketahui bahwa secara umum tidak ada perbedaan antara skala-skala iklim kelas yang dialami (actual) dengan iklim kelas yang diharap- 
kan (preferred) oleh peserta didik. Namun demikian, skala cohesiveness dan satisfaction pada kelas V SD Negeri 10 Ganting Koto Tangah menunjukkan perbedaan yang harus menjadi perhatian guru dan peneliti.

Dari simpulan tersebut, maka yang harus menjadi perhatian adalah bagaimana upaya yang dapat dilakukan untuk meningkatkan skala cohesiveness dan satisfaction yang dialami oleh peserta didik (actual form) dapat seperti yang diinginkan oleh peserta didik (preferred form).

Skala cohesiveness misalnya, dapat ditingkatkan dengan membuat proses pembelajaran berkelompok sehingga mengharuskan antara peserta didik yang satu berkolaborasi dengan peserta didik lainnya. Tugas kelompok dapat digunakan oleh guru untuk mendorong para peserta didik dalam kelompoknya berkomunikasi lebih intensif dan efektif dalam menyelesaikan tugas. Kondisi yang demikian diharapkan akan memicu keakraban atau cohesiveness diantara para peserta didik.

Sedangkan skala kepuasan diantaranya dapat diberikan oleh guru dengan memberikan kesempatan kepada para peserta didik untuk bertanya sepuas-puasnya kepada guru. Dalam hal yang demikian, guru pun harus memberikan respon atau jawaban yang memuaskan peserta didik. Kepuasan juga dapat dibantu oleh kelengkapan sumber serta sarana dan prasarana pembelajaran di kelas. Untuk hal yang terakhir ini, guru harus berkonsultasi dengan kepala sekolah agar sumber belajar, sarana dan prasrana pembelajaran di kelas menjadi lebih baik dibandingkan dengan kondisi sebelumnya. Hal-hal yang demikian inilah yang akan menjadi bahan diskusi dan perbaikan pada langkah-langkah berikutnya dari penelitian yang berkelanjutan ini. Langkah-langkah tersebut akan dilaksanakan pada penelitian tahap berikutnya.

\section{Daftar Pustaka}

Falsario. (2014). Classroom climate and academic performance of education Students'. De La Salle University: Manila.
Fisher, D. L. (1990). The assessment and change of classroom and School environment. Launceston.

Fisher, D. L., \& Fraser, B. J. (1982). Use of classroom environment scale in investigating relationship between achievement and environment. Journal of Science and Mathematics Education in South East Asia, 5(2), 5-9.

Fisher, D. L., \& Nair, C. S. (n.d.). Students' perceptions of tertiary science classroom environments. Journal of Science and Mathematics Education in South East Asia, XXIV(1), 50-66.

Fraser, B. J. (1986). Classroom environment. London: Croom Helm.

Fraser, B. J., \& Fisher, D. L. (1983). Use of actual and preferred classroom environment scales in person environment fit research. Journal of Educational Psychology, 75(2), 303-313.

Fraser, B. J., Seddon, T., \& Eagleson, J. (1982). "Use of student perceptions in facilitating improvement in classroom environment." The Australian Journal of Teacher Education, 7(1), 31-42.

Hadiyanto. (2004). Mencari sosok desentralisasi manajemen pendidikan di Indonesia. Jakarta: Rineka Cipta.

Hadiyanto. (2016). Teori dan pengembangan iklim kelas dan iklim sekolah. Jakarta: Kencana.

Hadiyanto, \& Kumaidi. (1998). Pengembangan dan pemvalidasian alat ukur iklim kelas di sekolah lanjutan tingkat pertama. Padang: IKIP Padang.

Hadiyanto, \& Mukti, B. (1997). Pengembangan dan Validasi Alat Ukur Iklim Kelas Sekolah Dasar. Padang: IKIP Padang.

Hyman, R. T. (1980). School administrator's handbook of teacher supervision and evaluation methods. New Jersey: Prentice Hall, Englewood Cliffs.

Info-Tasikmalaya. (2017). Ribuan guru gagal naik pangkat karena plagiat. 
Retrieved April 22, 2017, from

http://adstasik.blogspot.co.id/2015/0

8/guru-gagal-naik-pangkat.html

JPP. (2017). Mendikbud ingatkan Guru tidak lakukan plagiat. Retrieved April 1, 2017, from

http://jpp.go.id/teknologi/ pendidikan/304439-mendikbudingatkan-guru-tidak-lakukan-plagiat

Khine, M. S. (2001). Investigation of tertiary classroom learning environment in Singapore. Singapore: Nanyang Technological University.

Moos, R. H. (1979). Evaluating educational environments. Washington: Jossey-Bass Publishers.

Muhammad, A., Hadiyanto, \& Nurli. (1998). No Title. Padang.
Sutjipto, \& Hadiyanto. (2003). Upaya kepala sekolah dalam menciptakan iklim sekolah dasar di Jakarta. Jakarta.

Tarmidzi. (2006). Iklim Kelas dan Prestasi Belajar. Medan: Universitas Sumatera Utara.

Wahyuningrum. (2008). Hubungan kemampuan, kepuasan dan disiplin kerja dengan kinerja pegawai di Kecamatan Tanggungharjo Kabupaten Grobogan. Semarang: Universitas Negeri Semarang.

Zedan, R. (2010). New Dimensions in the Classroom Climate. Learning Environment, (13), 75-88. 